\title{
Estimation of the size of a coral reef fish population
}

\author{
G. Gaudian ${ }^{1}$, P. A. H. Medley ${ }^{1}$, R. F. G. Ormond ${ }^{2}$ \\ ${ }^{1}$ Fisheries Department Grand Turk, Turks \& Caicos Islands, British West Indies \\ ${ }^{2}$ TMRU, University of York, York YO1 5DD, United Kingdom
}

\begin{abstract}
The present study monitored a fish population before and after fishing within a marked area. Visual census counts along transects were used to estimate fish abundance inside and around the fishing area. The emperor Lethrinus borbonicus made up $64 \%$ of fish in terms of numbers and $44 \%$ of the catch in terms of weight. As fishing progressed, the catch per unit effort (CPUE) of $L$. borbonicus declined. Visual census counts of $L$. borbonicus were lower after fishing both inside and outside the fishing area. Linear models were used to calibrate CPUE and visual census data as indices of abundance to obtain 2 independent estimates of population size, which were found to be similar. These estimates further converged if the models included an estimate of the immigration rate into the fished population. The present study demonstrated that depletion experiments provide valuable information on coral reef fish populations, particularly for fisheries
\end{abstract}

KEY WORDS: Depletion experiment · Population size $\cdot$ Coral reef $\cdot$ Stock assessment $\cdot$ Visual census CPUE

\section{INTRODUCTION}

There is a growing body of literature describing the effects of fishing on coral reef fish assemblages. Studies indicate a significant change in catch per unit effort (CPUE), species composition and sizes of fish between exploited and unexploited reefs (e.g. Ferry \& Kohler 1987, Koslow et al. 1988, Russ \& Alcala 1989, Alcala \& Russ 1990). These results confirm that coral reef fisheries have a significant impact on fish assemblages, which suggests that some of the rationale underlying fish stock assessment based on length-frequency is valid. This indicates, in turn, the potential value of protected areas. However quantifying and modelling the effects of recruitment, natural mortality and movement still presents problems for fisheries management.

Munro \& Williams (1985) gave a number of research priorities for fisheries on coral reefs. They suggested that direct experiments are needed to clarify how results observed for small reef species might relate to larger fish. They also emphasized the importance of gear selectivity and the spatial and temporal scale of experiments. Experiments have been used by a num- ber of researchers to study the spatial distribution and recruitment of reef fish (e.g. Doherty 1982, Eckert 1984, Meekan 1988). These studies have tended to concentrate on larval recruitment to the reef for a variety of species (Doherty \& Williams 1988), but the value of the results to fisheries management is questionable since they deal with small, often territorial, fishes which have little importance for fisheries. The experiment carried out by Beinssen (1988) at Boult Reef, Great Barrier Reef, is more appropriate for generating useful fisheries information, at least in the short term. By recording catch and effort and independently monitoring the population size of the grouper Plectropomus leopardus over a short period, Beinssen was able to estimate catchability, and hence fishing mortality. Similar experimental approaches have been used for some time in deep water fisheries (e.g. Polovina 1986, Ralston et al. 1986).

Although most fisheries models ignore spatial distribution and movement, these factors may be significant in determining the catch rate, and hence the dynamics of a fishery (Hilborn \& Walters 1992). Many ecological studies of fish have concentrated on relatively sedentary taxa (e.g. Pomacentridae), so that movement and 
its effects on population size and structure have generally not been considered (Jones 1991). However, the spatial distribution of stocks may play a significant part in coral reef fisheries dynamics since reefs are intrinsically patchy. For instance, movement has been found to be important in determining distributions of surgeon fish (Robertson 1988a) and the pomacentrid Abudefduf saxatilis (Robertson 1988b). It seems likely that movement will be important in species which dominate catches, such as lethrinids and lutjanids.

This study developed a method to estimate the unexploited population size and fishing mortality of a fish stock. In addition, the method used provided data suitable for the analysis of the distribution and movement of fish and for the calibration of visual census to estimate abundance. The short-term nature of the study made it appropriate for the analysis of fishing mortality and migration since on this scale these factors should dominate the slower processes of natural mortality and recruitment. Although other fish species were monitored, the results presented here concentrate primarily on 1 species, Lethrinus borbonicus, which made up most of the catch.

\section{METHODS}

Depletion models. If an index of abundance, proportional to the size of a closed population, is obtained before and after a given number of animals are removed, the initial size of the population can be calculated. For instance, if an index, such as a count along a transect or CPUE, was 24 before fishing and was reduced to 16 after removing 1000 fish, then 1000 fish would represent $(24-16) / 24=33 \%$ of the population. Hence, the initial population size would have been 3000 fish. This is true irrespective of the biology of the fish, as long as the population is closed and the index is proportional to abundance. For many populations there is reasonable doubt as to whether the index is well behaved enough or whether the population is sufficiently closed to recruitment, mortality, immigration and emigration to provide a reasonable estimate.

For the current study an experiment was designed to isolate these factors as far as possible to see whether adaptations of the basic model could be used in coral reef fish stock assessment. First, a relatively short time period was chosen to ensure that bias introduced by mortality and recruitment would be small. Second, 2 independent indices were used for which it seemed reasonable to assume they were proportional to abundance over a fairly wide range of fish densities. Both indices are zero when fish density is zero and increase as density increases, although at very high densities some saturation of the indices is likely. Very different

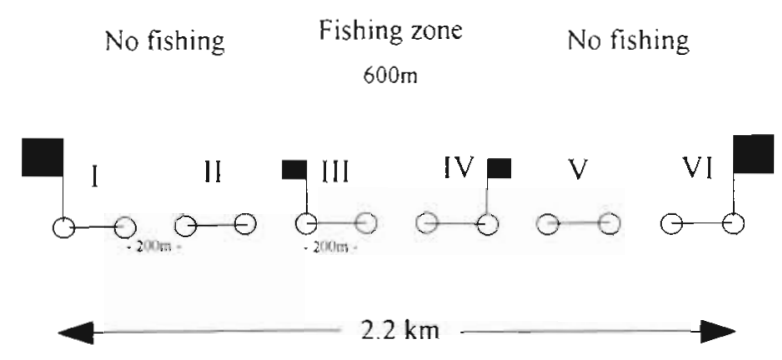

Fig. 1. Diagram showing relative positions of buoys (0) marking each station and flags ( $\mathbf{\square}$ ) delineating the zones

estimates of initial population size derived from these 2 indices would suggest that at least 1 of the indices is non-linear, and this would considerably reduce the amount of confidence which could be placed in the model. Emigration and immigration are more difficult to deal with since these will have a large impact on population size over a short period. Therefore, an attempt was made to monitor net movement into and out of the population directly.

Study site and experimental design. The study site was siludieu dit the southern end of Zanzibar Island, off the east coast of Tanzania, an area fished on a subsistence level by 2 local villages during the northeast monsoon from December to March. It is a fringing reef with no nearby reefs offshore, so reef fish movement could be assumed to be predominantly along the reef. The reef had been subjected to little previous fishing, so any observed changes could be attributed to the experimental treatment rather than the fishery. In spring 1991, six $200 \mathrm{~m}$ long transect lines were laid in sequence along the fringing reef at a depth ranging between 6 and $9 \mathrm{~m}$, following the contours of the reef (Fig. 1), each $200 \mathrm{~m}$ transect constituting a station. The 6 stations were $200 \mathrm{~m}$ apart, so that the overall study site was $2.2 \mathrm{~km}$ long. A $600 \mathrm{~m}$ section, forming the experimental fishing area, was marked in the centre of the study area (Stns III and IV).

Fish counts. A list of 40 reef fish species to be included in the census was compiled, covering both species common in the catch of local fishermen and several species which were rarely caught. All fish seen were counted during the $20 \mathrm{~min}$ swim at $2 \mathrm{~m}$ above the substrate along the $200 \mathrm{~m}$ transect line. Each of the 6 stations was censused 12 times before and 12 times after the fishing period, starting $6 \mathrm{~d}$ before the fishing period and commencing immediately after the fishing for a further $6 \mathrm{~d}$. The 6 stations were sampled in a random sequence 3 times, and on each visit to a station 4 repeat transects were completed. For the analysis, fish counts could be compared directly, as the amount of time spent on each count was the same and other factors recorded (e.g. the person doing the census) were found to have no significant effect. 
Fishing period. The fishing period inside the $600 \mathrm{~m}$ zone lasted $11 \mathrm{~d}$. Fishermen used baited handlines, with 1 hook (size 14) per line and up to 3 lines per boat. Detailed daily records were made of the number of boats, number of lines per boat and time each boat spent fishing. The catch was examined, recording number, weight, length and species of each individual fish.

Statistical models. Encounters in a fish census, if the probability of an encounter is constant, can be described as a Poisson process (Cox \& Miller 1977), so the numbers of fish encountered should follow the Poisson rather than normal distribution. Similarly, if fish move randomly, the probability distribution of the catch from a hook would be Poisson, with the mean dependent upon the population density of fish and the soak time of the hook. Because the variance of the Poisson distribution changes with the mean, a least-squares fit will not give maximum likelihood estimates for model parameters. In addition, leastsquares assumes that negative values are possible, which in this case is clearly false. However, if the mean is large, the normal distribution will still provide a reasonable approximation to the Poisson, and there should be little difference between the leastsquares and maximum likelihood parameter estimates. Unfortunately, this approximation would be too inaccurate for the small data set available for this study. The only alternative to using another log-likelihood function is to transform the data. Although this will correct for the changing variance, it also alters the relationship between dependent and independent variables. Unless the transformation is fortunate enough to produce a relationship similar to that described by the models, they will fit the transformed data poorly. It is, therefore, better to keep the error and linear models separate, so each can be defined independently.

It is unlikely that catch or census data will be exactly Poisson, although the variance should still increase with the mean. Fish aggregation will make the data over-dispersed relative to the Poisson, so it will be necessary to use the quasi-likelihood assumption that the variance is proportional, rather than equal, to the mean. For all the following models, the error distribution is Poisson, the link function is the natural logarithm and the scale parameter is estimated from the data (see McCullagh \& Nelder 1983). Although this model will still produce maximum likelihood estimates, it cannot be certain that the deviance (derived from the Poisson log-likelihood) follows the chisquared distribution. Therefore, strictly speaking, testing for the inclusion of terms using the F-ratio statistic is inappropriate, although the statistic can still be used to indicate a variable's importance. The statistical package GLIM (1985) was used to fit the visual census models.

A log-linear model with factors indicating the station, and whether the count took place before or after the fishing period, was used to estimate the number of fish counted on a particular census.

$$
\mu=\exp \left(\beta_{0}+S+E+S \cdot E\right)
$$

where $\mu$ expected number of fish in a count; $\beta_{0}=$ constant; $S=$ effect due to the station; $E=$ effect due to fishing; $S \cdot E=$ interaction term. If abundance between stations and before/after fishing are different, one would expect the station $(S)$ and fishing $(E)$ factors to be significant. Most importantly, if there was a change in the distribution of the remaining fish after fishing, it would be expected that the interaction term $(S \cdot E)$ would be significant. The parameter $E$ can be used to derive the proportional change in abundance of the stock.

An immigration term can be included into this model, allowing for a constant immigration of fish with no emigration. This would result in a linear increase in the census counts from the end of the fishing period.

$$
\mu=\exp \left[\beta_{0}+S+E+\ln (1+I \times t)\right]
$$

where $I=$ immigration rate; $t=$ no. of days since fishing ceased. The immigration parameter $(I)$ can be negative, representing net emigration, or positive, indicating net immigration, and is estimated as a proportion of the population remaining at the end of the fishing period. Only data collected after the fishing period was used to estimate the immigration rate $(t=0$ for all days prior to fishing), so essentially this equation measured the rate of recovery. The population was, therefore, assumed to be at equilibrium before the fishing period. The fitting procedure required a second level of iteration in GLIM, because the immigration parameter is not linear in relation to the other parameters. In fitting the parameter, an initial value of 0.0 was chosen and a bootstrap method was used to estimate the standard error.

The alternative approach is to use the CPUE as the abundance index to study the population changes. For comparison with other work, the CPUE analysis was carried out using the Leslie method, based on a leastsquares linear regression (Seber 1973) using the CEDA computer package (CEDA 1992). For this analysis, the data were combined into daily totals of hook-hours fishing and total catch per day.

$$
\mu_{k}=q N_{0}-q \sum_{i=0}^{k-1} C_{i}
$$

where $\mu_{k}=$ expected catch per unit effort on Day $k$; $N_{0}=$ initial population size; $C_{j}=$ catch on Day $i ; q=$ catchability. 


\section{RESULTS}

\section{Fish counts}

The analysis of the data concentrated on Lethrinus borbonicus, the most important constituent of the catch. Fitting the basic linear model to the census data for L. borbonicus (Eq. 1), it was shown that the most important factor was clearly the station (Table 1). Station VI at the eastern end of the experimental area appeared to have considerably more individuals than any other station, whereas Stns I and II consistently had fewer. The post-fishing term estimated the difference in counts after fishing. There was a decline in numbers observed after the fishing period (Fig. 2). The interaction term between station and post-fishing was relatively small and explained little of the variation (approximate $F$-ratio statistic $1.90, \mathrm{df}=5: 140$ ). This suggests that fishing did not affect abundance differently at each station.

Assuming a closed population (i.e. natural mortality, migration and recruitment are insignificant), the proportional decine in the population can be equated with the estimated decline in visual census counts.

$$
\begin{array}{r}
\frac{N_{0}-C}{N_{0}}=\exp (E) \\
N_{0}=\frac{C}{1-\exp (E)}=5244
\end{array}
$$

where $C=$ total catch $=2742 ; E=$ decline in abundance $=-0.74$ (from Table 1 ). The $95 \%$ confidence interval for the initial pre-fishing population size of Lethrinus borbonicus was 4278 and 7491 (calculated from estimate standard errors $0.74 \pm 0.145$; Table 1 ).

The increase in the counts during the period after fishing, which implies immigration, was small compared to the total deviance (Table 2). Although immi-

Table 1. Analysis of deviance from fitting the log-linear model without the interaction term (see Eq. 1) to visual census counts of Lethrinus borbonicus. Total deviance given ${ }_{i}$ all other deviances are change in the Poisson log-likelihood function associated with the particular term. Station estimates indicate difference from Stn I and the post-fishing estimate from the period before fishing

\begin{tabular}{lrrccc|}
\hline Term & df & Deviance & Variable & Estimate & SE \\
\hline Total & 151 & 3250.0 & Constant & 0.956 & 0.598 \\
Station & 5 & 1890.2 & Stn II & 2.135 & 0.627 \\
& & & Stn III & 2.257 & 0.627 \\
& & & Stn IV & 1.262 & 0.674 \\
& & & Stn V & 2.049 & 0.630 \\
Post-fishing & 1 & 222.1 & Stn VI & 3.784 & 0.602 \\
& & & & -0.740 & 0.145 \\
\hline
\end{tabular}

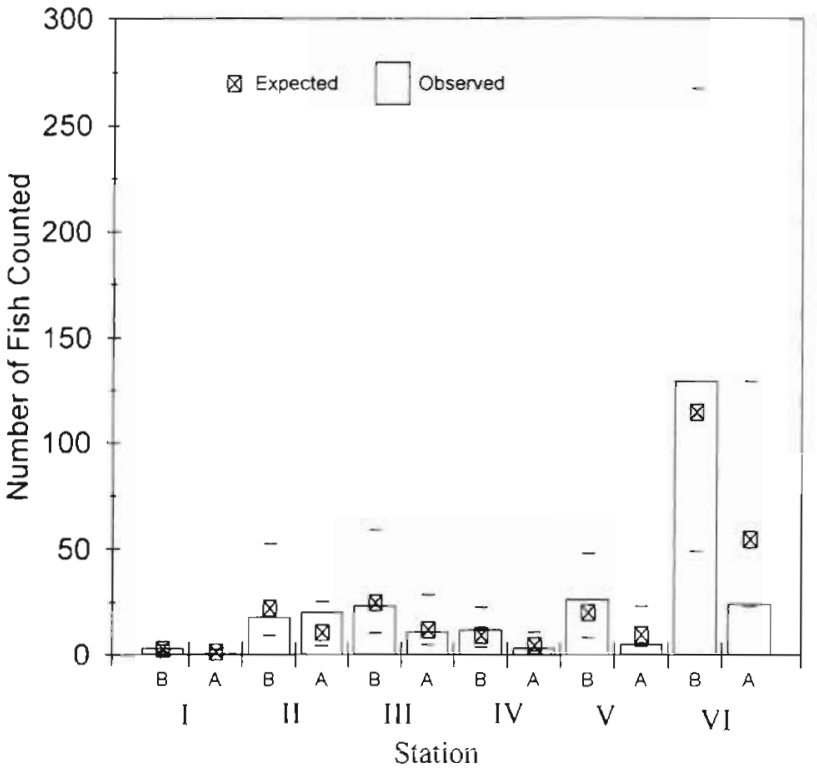

Fig. 2. Lethrinus borbonicus. Observed fish counts made at each station (B) before and (A) after fishing. Expected counts are generated from the log-linear model (Eq. 1) and maximum likelihond estimates (Table 1) Rars around mean indicate SE

gration explains little of the variation in counts (approximate $F$-ratio $=2.67, \mathrm{df}=1: 144$ ), it is not unreasonable to assume that immigration occurred and to use the estimate in other calculations.

With immigration and emigration dependent on the size of the resident population, it might be expected that the increase in population will be asymptotic. However, an asymptotic function provided a worse fit to the present data than the constant immigration model, so constant immigration was assumed adequate as long as the model is not used to extrapolate beyond the observations.

The initial population size can be re-estimated assuming immigration by combining Eqs. (2) and (4).

$$
N_{0}=\frac{C}{1-(1-I \times t) \exp (E)}=2656
$$

where $E=$ decline in abundance immediately at the end of the fishing period $=-1.206$ (from Table 2$) ; I=$ immigration rate $=0.1008$ (from Table 2); $t=$ length of the fishing period $=11 \mathrm{~d}$. A constant immigration rate of 80.1 fish $\mathrm{d}^{-1}$ can be derived from this initial population size estimate.

\section{Fishing}

An average of 13.1 hand lines were fishing each day with 1 baited hook on each line. At the end of the $11 \mathrm{~d}$ period 4267 fish weighing in total $544 \mathrm{~kg}$ had been caught. Lethrinus borbonicus dominated the catch, 
Table 2. Results from fitting an additional term to the model from Table 1 to estimate the immigration rate $(I)$ of Lethrinus

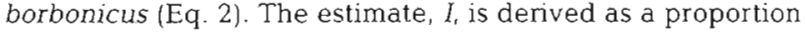
of the population size immediately after fishing, so population size needs to be known to calculate immigration in numbers of fish. Allowing for immigration increases the proportion of the initial population removed by fishing, as indicated by the post-fishing estimate which is lower than in Table 1

\begin{tabular}{|lccccc|}
\hline Term & df & Deviance & Variable & Estimate & SE \\
\hline Post-fishing & 1 & 222.1 & $E$ & -1.206 & 0.143 \\
$\begin{array}{l}\text { Immigration } \\
\text { rate }\end{array}$ & 1 & 20.3 & $I$ & 0.1008 & 0.089 \\
\hline
\end{tabular}

forming $64 \%$ of fish in terms of numbers and $44 \%$ of the catch in terms of weight. The average catch rate was 29.8 fish or $3.8 \mathrm{~kg} l i n \mathrm{e}^{-1} \mathrm{~d}^{-1}$.

If catches were related to stock size and the stock size was decreasing, the CPUE should have declined. Although the results were difficult to interpret due to the high variability in the catch rates, an overall decline in the CPUE, driven by the Lethrinus borbonicus catch, was detectable. The low catch rate apparent on the first day was due to an inaccurate assessment of effort, since much time was wasted in organising the fishing operation. Data collected on this day was, therefore, deleted from the analysis. The CPUE LeslieDelury population model (Eq. 3) with a gamma error model (CEDA 1992) gave a reasonably good fit to the data. Without immigration the estimated population size $\left(N_{0}\right)$ is 4261 and catchability $(q) 0.0022$. With immi-

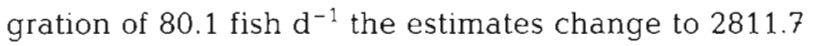
fish and catchability to 0.0035 . The catchability estimate, which multiplied by fishing effort gives fishing mortality, is considerably higher when immigration is taken into account.

\section{DISCUSSION}

Since Brock (1954) visual census has been widely used in the assessment of coral reef fish abundance (e.g. Jones \& Chase 1975, Robertson \& Lassig 1980, Fowler 1987). However, visual census has always included a significant element of error (Sale \& Douglas 1981), particularly of cryptic or abundant species (Sale \& Sharp 1983). One approach is to increase the accuracy of abundance estimates by improving the census design (Fowler 1987). A complimentary approach presented in this study is to use a model to deal with problems of bias in census data.

The use of CPUE as an abundance index has many problems owing to its dependence on other factors besides abundance, for instance fish behaviour and size, and changes in fishing gear (Hilborn \& Walters 1992). The solution has been to use a parameter relating CPUE to stock size (catchability), which can change over time and be estimated from catch and effort data. The same principle can be used to calibrate visual census data, where a count is assumed to be proportional to the population size rather than used as a direct measure of density. This approach may solve many of the problems associated with cryptic or abundant species since the calibration parameter can correct the different error for each species. However the price paid for the relaxation of the assumption that visual censuses are $100 \%$ accurate is an increase in the number of parameters which need to be estimated. The information required to estimate these parameters can be obtained from depletion experiments (Seber 1973, Cowx 1983).

In order to estimate the size of a population it is important to know precisely what an abundance index is measuring. CPUE as an abundance index is most likely to be affected by changes in catchability as fishing progresses. For instance, in this case fish may have become hook-shy, or if the hooks differentially took particular sizes of fish, the catchability would have decreased as the size composition of the stock changed. In contrast, it is hard to see how the visual census index would have been affected by the fishing event, although it would still be subject to other errors. For instance, the fish may react to the divers themselves, becoming less shy as they regularly see divers on the reef. The similarity of the population estimates (Table 3) suggests these errors are small, and the assumption that the indices are proportional to population size is a reasonable one in this case. Obviously, the assumption would still need to be checked for other species and in other locations.

Even though the index may be acceptable, the observed population size may still be controlled to a significant extent by fish movement. Visual census and

Table 3. Initial population $\left(N_{0}\right)$ estimates of Lethrinus borbonicus using the 2 indices of abundance (visual census and catch per unit effort, CPUE) and 2 model types (with and without immigration). Confidence intervals (CI) for the models including immigration assume the immigration estimate has no variability. This allows comparison of the estimates derived from CPUE, for which variability in the estimate could not be included, and from visual census

\begin{tabular}{|lcccc|}
\hline \multirow{2}{*}{ Model type } & \multicolumn{2}{c}{ Visual census index } & \multicolumn{2}{c|}{ CPUE index } \\
& Estimate & $95 \% \mathrm{CI}$ & Estimate & $95 \% \mathrm{CI}$ \\
\hline $\begin{array}{l}\text { Excluding } \\
\text { immigration }\end{array}$ & 5244 & $4278-7491$ & 4261 & $3098-16475$ \\
$\begin{array}{l}\text { Including } \\
\text { immigration }\end{array}$ & 2656 & $2629-2676$ & 2811 & $2071-7654$ \\
\hline
\end{tabular}


CPUE may only measure a small area occupied by a population. The simplest movement model assumes that fish move randomly among areas, so if this movement is rapid enough a reduction in population size should be observed equally over all areas even when fish are removed from an area smaller than its range. This was consistent with the decline in counts after fishing observed for Lethrinus borbonicus (Fig. 2). If this model is correct, visual census and CPUE indices can measure changes in population size independent of the location within the population range. However, absolute sizes of these indices will depend on location, so to monitor a population subsequent counts must be repeated at the same locations or should be chosen randomly. Randomly chosen locations will require more data to detect changes since the error variance is higher, but this procedure will avoid problems associated with local changes of other environmental variables which may affect the index but not the population being monitored. In a CPUE time series it would be difficult to know when fishing locations had changed. For the analysis of CPUE data it may be necessary to understand how fishermen choose their tishing area, so some adjustment can be made for changes in fishing location.

Depletion experiments with closed populations are rare. This has led to the development of models including movement and recruitment (Sainsbury 1984). In the present experiment it was possible to estimate the immigration rate as direct observations were made on changes in distribution of the Lethrinus borbonicus population. Immigration could explain the difference between the independent estimates of the initial population size using visual census and CPUE indices (Table 3). The similarity of the estimates suggests that these indices are related to the population size in a similar way. However, the immigration rate standard error (Table 2) prevents any firm conclusions being made. Even with an immigration rate as low as $3 \%$ of the initial population $\mathrm{d}^{-1}$, the estimates of population size and associated parameters were greatly affected. Given the high variability in both visual census and CPUE data, an accurate estimation of parameters with such sensitive values will require a larger data set. Increasing the time period of the experiment may call into question assumptions about recruitment and mortality and should be avoided if possible. However, to obtain a more accurate estimate of the immigration rate the sampling effort could be increased after the fishing period by increasing both the number of stations and the sampling frequency. For the current experiment the size of the immigration parameter suggests that approximately 3 to 4 times as much data would be needed before the $95 \%$ confidence interval would exclude zero.
It is not clear over how large an area the initial population of Lethrinus borbonicus was distributed. It appears that the population covered at least the length of the study area $(2.2 \mathrm{~km})$. The average density estimated from visual census counts before fishing was $5.89 \mathrm{~L}$. borbonicus per $200 \times 10 \mathrm{~m}$ of reef, and as the reef was approximately $100 \mathrm{~m}$ wide, the length of reef covered by 2656 fish (Table 3) will be $9.0 \mathrm{~km}$. Similar calculations for the other estimates of initial population size place the reef length between 9 and $20 \mathrm{~km}$. This estimate is probably the maximum area over which the population was distributed, since observers will tend to underestimate number of fish. In addition the location was not chosen randomly, therefore it is not possible to assume that the density estimates used in the calculation are representative over the range of the population. However, it does suggest that a $20 \mathrm{~km}$ stretch of reef with more widely dispersed census stations would be a more appropriate scale for assessing the area occupied by the fish population.

A second fundamental question is whether the measure of population size relates to a real discrete popuIation on the reef. it is pussible tú ótatain such estimates even if the population was continuous over a very large area and redistribution was through a diffusion process. To verify that a single, discrete population was measured would require that adjacent populations remain relatively unaffected by fishing and that a barrier exists between the populations with measurable migration between them.

Depletion experiments may be the only cost-effective method for the accurate stock assessment of many coral reef fish species. However, experimental designs that will provide adequate assessments of each species covering the entire fishing area have yet to be developed.

Acknowledgements. We thank Pete Hayward, Matt Richmond and Dave Wachenfeld for assisting with the data collection and Mark Bravington for discussions about the data analysis. We are grateful to Dr Ngoile (Institute of Marine Science), Mr Makame (Department of Fisheries), Mr Nguli (Commission for Science and Technology) and the villages Kizimkasi Dumbani and Mkunguni for their co-operation and support. The project was financed by the Overseas Development Administration and administered by the Marine Resources Assessment Group Ltd, London, and the Tropical Marine Research Unit, York, UK.

\section{LITERATURE CITED}

Alcala AC, Russ GR (1990) A direct test of the effects of protective management on abundance and yield of tropical marine resources. J Cons int Explor Mer 46:40-47

Beinssen K (1988) Boult reef revisited. Reeflections 21:8-9

Brock VE (1954) A method of estimating reef fish populations J Wildl Mgmt 18:297-308

CEDA (1992) Catch and effort data analysis, Version 1.0 MRAG Ltd, 27 Campden Street, London W8 7EP, UK 
Cowx IG (1983) Review of the methods for estimating fish population size from survey removal data. Fish Mgmt 14 $67-82$

Cox DR, Miller HD (1977) The theory of stochastic processes. Chapman and Hall, New York

Doherty PJ (1982) Coral reef fishes: recruitment limited assemblages? Proc 4th int Symp Coral Reef 2:465-470

Doherty PJ, Williams DM (1988) The replenishment of coral reef populations. Oceanogr mar Biol A Rev 26:487-551

Eckert GJ (1984) Annual and spatial variation in recruitment of labroid fishes among seven reefs in the Capricorn/ Bunker Group, Great Barrier Reef. Mar Biol 78:123-127

Ferry RE, Kohler CC (1987) Effects of trap fishing on fish populations inhabiting a fringing coral reef. N Am J Fish Mgmt 7:580-588

Fowler AJ (1987) The development of sampling strategies for population studies of coral reef fishes. A case study. Coral Reefs 6:49-58

GLIM (1985) Generalised linear interactive modelling Manual, Release 377. NAG, Oxford

Hilborn R, Walters CJ (1992) Quantitative fish stock assessment: choice, dynamics and uncertainty. Chapman and Hall, New York

Jones GP (1991) Postrecruitment processes in the ecology of coral reef fish populations: a multifactorial perspective. In: Sale PF (ed) The ecology of fishes on coral reefs. Academic Press, San Diego, p 294-328

Jones RS, Chase JA (1975) Community structure and distribution of fishes in an enclosed island lagoon in Guam. Micronesica 11:127-148

Koslow JA, Hanley F, Wicklund R (1988) Effects of fishing on reef fish communities at Pedro Bank and Port Royal Cays, Jamaica. Mar Ecol Prog Ser 43:201-212

McCullagh P, Nelder JA (1983) Generalized linear models. Chapman and Hall

This article was submitted to the editor
Meekan MG (1988) Settlement and mortality of juvenile fishes at Lizard Island Northern Great Barrier Reef. Proc 6th int Symp Coral Reef 2:779-784

Munro, JL, Williams, DMcB (1985) Assessment and management of coral reef fisheries: biological, environmental and socio-economic aspects. Proc 5th int Coral Reef Congr 4: $543-581$

Polovina JJ (1986) A variable catchability version of the Leslie model with application to an intensive fishing experiment on a multispecies stock. Fish Bull US 84:423-428

Ralston S, Gooding RM, Ludwig GM (1986) An ecological survey and comparison of bottom fish resource assessments (submersible versus handline fishing) at Johnston Atoll. Fish Bull US 84:141-155

Robertson DR (1988a) Abundances of surgeonfishes on patch reefs in Caribbean Panama. Due to settlement or post-settlement events? Mar Biol 97:495-501

Robertson DR (1988b) Settlement and population dynamics of Abudefduf saxatilis on patch reefs in Caribbean Panama. Proc 6th int Symp Coral Reefs 2:839-843

Robertson DR, Lassig B (1980) Spatial distribution patterns and coexistence of a group of territorial damselfishes from the Great Barrier Reef. Bull mar Sci 30:187-203

Russ GR, Alcala AC (1989) Effects of intense fishing pressure on an assemblage of coral reef fishes. Mar Ecol Prog Ser $56: 13-27$

Sainsbury K (1984) Optimal mesh size for tropical multispecies trawl fisheries. J Cons int Explor Mer 41:129-139

Sale PF, Douglas WA (1981) Precision and accuracy of visual census technique for fish assemblages on coral patch reefs. Environ Biol Fish 6:333-339

Sale PF, Sharp BJ (1983) Correction for bias in visual transect censuses of coral reef fishes. Coral Reefs $2: 37-42$

Seber GAF (1973) The estimation of animal abundance and related parameters, 1st edn. Griffin, London

Manuscript first received: March 25, 1994

Revised version accepted: January 18, 1995 